\title{
Demand-Adjusted Shelf Availability Parameters: A Second Look
}

\section{Philip Schwarz}

The application of Kantor's demand-adjusted shelf availability model to a medium-sized academic library is described. The model can be applied in a working library environment with relative ease. The data indicate that there are significant differences in shelf availability when the data are sorted, adjusted, and analyzed by last circulation date, acquisition date, and imprint date. There is also a significant difference between the results of data gathered during periods of low and high use.

his research report is the second in a series. The papers describe the use of scientific management techniques to evaluate and describe various library operations and services, in order that managerial decisions may be made on a rational rather than an intuitional basis. The previous publication in this series was: Philip Schwarz and Linda Olson, "Examination of Potential Management Decisions Based upon a Core Collection Derived from Last Circulation Date Data" (Menomonie, Wis. Research Report no.1. U.S., Educational Resources Information Center, ERIC Document ED 214 496, Aug. 1982).

\section{BACKGROUND}

In an article appearing in the May 1981 Journal of Academic Librarianship, Paul Kantor described a simple theoretical model for determining shelf availability for library materials. ${ }^{1}$ The purpose of this paper is to apply this model to a working library environment and in the process examine several additional considerations not discussed in the Kantor article. These include: (1) gathering data on the time re- quired to apply the model developed by Kantor to a working library environment; (2) determining demand-adjusted shelf availability for a medium-sized university library; (3) determining whether there is any significant difference between the results of data expostulated in what Kantor describes as a naive fashion, and adjusted data sorted by last circulation date, acquisition ciate, and imprint date; and (4) determine the degree of difference between stack availability as recorded during the initial weeks of the semester when demand for materials is low as compared to the latter weeks of a semester when material is in heavy demand.

Historically, two approaches have been used to determine shelf availability in libraries. Shelf availability, as used in this paper, is the probability that a patron going to the shelf will find the item he is looking for. One approach to this problem is the collection of data based on expressed demand and described in papers by Buckland, Kantor, and others. ${ }^{2}$ Using this technique, demand as expressed by users is measured by actually surveying library users. The user is handed a form or a sur-

Philip Schwarz is special assistant for automation development, University of Wisconsin-Stout, Menomonie, Wisconsin.

The author wishes to thank Dr. Paul Kantor for commenting on the data. 
vey worker accompanies the patron around the library and determines the number of items found and the number of items not found. For those items not found, data are gathered to determine the reasons why they are not found. Using this technique, one can identify the potential impact of the various ways a user can be frustrated in his search for library materials. Sources of frustration in order of logical occurrence are: (1) collection development failure-the library has never acquired the item desired by the patron; (2) the patron does not have the necessary skills to use the catalog successfully; (3) the item is checked out; (4) the item is missing from its appropriate location on the shelf; (5) and lastly, the item is on the shelf in its proper location but for some reason the patron cannot locate it. The overall document availability is the product of all of these factors. Although providing a wide range of useful management data, this technique requires considerable effort to administer.

A simpler technique was introduced by Kaske and elaborated on by Altman and de Prospo. ${ }^{3}$ This technique utilizes a small sample drawn from the shelflist. Items in the sample are checked against the stacks and circulation records to determine the percentage of items not found. This approach provides less management information than the first technique described. One can only determine if the item is in circulation or if it is missing from its proper shelf location. It does not provide information regarding the adequacy of collection development policies, patron skills in using the catalog, or patron skills in locating materials in the collection. In addition, as Kantor points out, the data which this technique provides on circulation interference and on "other" factors are subject to inherent bias because of the failure to adjust for the fact that not all materials are equally in demand. ${ }^{4}$ The importance of this fact could have a significant impact upon the findings when using this technique. For example, libraries with very old and large collections are likely to find that the collection extends far beyond the interest of the current users. As a result, data gathered using this technique are likely to overestimate the probability that an item, in the relatively small subset of materials currently in demand, will be found on the shelf. The items in high demand are precisely the ones that are likely to be in circulation or not available for circulation for some reason. It is this issue that this paper is intended to address.

\section{METHODOLOGY}

Several points are worth noting in connection with this study. The author was able to conduct the comparative analysis of data involving last circulation date, acquisition date, and imprint date because the library utilized a circulation system that retained information regarding item circulation activity. It is also worth noting that all library users are limited to a twenty-eight-day circulation period. This may be important if other libraries intend to compare their findings with data presented in this study.

The first phase of the study involved the selection of a random sample of 504 items drawn from a total population of 141,000 . The random sample was created using a standard computer random number generator program. The numbers, once generated, were sorted into numerical sequence to facilitate matching against the numerical sequence of the shelflist drawers. Once this was completed, the survey worker went to the shelflist to gather the sample. The survey worker opened the appropriate drawer and laid a ruler alongside the cards. A second set of random numbers was used to select the card or cards in each drawer corresponding to the number of samples to be drawn from the drawer. For example, if two samples were to be drawn from a drawer and the random number table indicated they should be drawn from one and ten inches, slips were inserted in the shelflist at these points. The call number, imprint date, and the date of acquisition for each sample were recorded on the data collection form shown in figure 1 . If the card happened to be for an item with multiple volumes, a second random number table was used to select the volume number to be recorded on the data collection form.

The second phase of the study involved 


SAMPLE
NUMBER

FIGURE 1

Data Collection Form

checking on the status of each item in the sample. Kantor suggests starting with the circulation records. ${ }^{5}$ However, the author suggests that it would be more efficient to begin in the stacks. A quick calculation of the number of items in circulation indicated that only a small percentage of the collection (approximately 6 percent) would likely be in circulation at any one time. As a result, the survey worker first went to the stacks and searched for each item listed on the data collection form. If the item was located, the last circulation date and the disposition code (in this case a 1 for stacks) was recorded in the appropriate columns on the data collection form. If the item had not circulated, the acquisition date was duplicated in the last circulation date column on the data collection form.

When the survey worker neared completion of his shift, he stopped searching in the stacks and went to the circulation desk to search the circulation records for items not located in the stack search. If the item was located in the circulation records, indicating that it was not available for circulation, the previous (next to last) circulation date was recorded in the last circulation date column on the date collection form. If this date was not available, the date of acquisition was recorded in the last circulation date column. A code (2) was recorded in the disposition column on the data collection form indicating the item was in circulation.

In cases where an item was not located, a 0 was recorded in the disposition column. Items not located were later searched for on several occasions. If found, the last circulation date was recorded in the appropriate column on the data collection form. If the last circulation date was not available, the date of acquisition was duplicated in the last circulation date column. Items falling into the "other" category were either misshelved, in transit, in use within the library, missing, or incorrectly processed. No attempt was made to quantify this information although it would be relatively easy to do and would be required if the library felt this category could be a significant factor in the availability analysis.

The final step, prior to the data analysis, involved keypunching the sample number, imprint date, acquisition date, and last circulation date onto IBM cards for later sorting and tallying. The subsequent analysis of the data is discussed in the following section.

\section{ANALYSIS OF DATA}

One of the objectives of the study was to determine the personnel requirements for conducting a study of the type described in this paper. Table 1 provides this information. As can be seen, the two most time-consuming aspects of a study of this type involve the selection of the sample from the shelflist and the time required to search for the material. There would be a slight savings in time if the survey worker had not opened each item to determine the last circulation date, however, the total savings in time would have been less than two hours. Information regarding the time required for data analysis was not included. It should be noted that it is not a time-consuming activity. An IBM Per- 
TABLE 1

PERSONNEL REQUIREMENTS FOR CONDUCTING THE AVAILABILITY ANALYSIS

Activity Time

Developing strategy

Selecting sample from the shelflist

Developing programming requirements

sonal Computer and the VisiCalc software were utilized to produce the statistical tables. Development of the master tables and calculation of the data presented in the tables required only a few hours.

A second objective of the study was to determine if there was any significant difference between the results of data expostulated in what Kantor describes as naive fashion and adjusted data sorted by last circulation date, acquisition date, and imprint date. The results of this analysis are shown in tables 2 through 5 and discussed below.

Table 2 displays what Kantor refers to as naive data, that is, unadjusted data which assume that demand is distributed uniformly over the collection. The data shown in this table were gathered during a period of high circulation. The data are sorted by last circulation date and divided into three equal categories labeled young, middle, and elder. Within each category, material is identified as being in circulation, on the shelf, or "other." The young category represents material with a last circulation date within the last eighteen months. The middle category represents material with a last circulation date of between nineteen and seventy-two months. The elder, and final, category represents material that has not circulated within the last seventy-three months.

The total number of items in the young category is found to be 168 , of which 24 are circulating, 132 are on the shelves, and 12 cannot be accounted for. There are 168 items in the middle category of which 1 is circulating, 154 are on the shelves, and 13 cannot be accounted for. The elder category also contains 168 items of which none are circulating, 151 are on the shelves, and 17 cannot be accounted for. It is clear from the table that most of the items circulating fall into the young category. The impor- tance of this fact will be examined in greater detail in the discussion of the next table.

As table 2 also indicates, the circulation dysfunction, that is the failure rate resulting from an item being in circulation, for the naive analysis is 4.9 percent. This was calculated by dividing the number of items in circulation (25) by the total number of items in the sample (504). The "other" category dysfunction, that is the failure rate resulting from not being able to account for an item, is 8.7 percent. This was calculated by dividing the total number of items in the "other" category (42) by the difference between the total number of items in the sample (504) less the total number in circulation (25). The total stack dysfunction, that is the failure rate resulting from not being able to locate an item in the stacks, is 13.2 percent and is determined by adding the total number of items in circulation (25) to the total number of items in the "other" category (42) and dividing the resulting total by the total number of items in the sample (504). The stack availability is found by subtracting the stack dysfunction (13.2 percent) from 100 percent which, in this case, is 86.7 percent. That is, a patron going to the stacks looking for an item found in the public catalog, could potentially find it on the shelf 86.7 percent of the time.

As mentioned earlier, this analysis assumes that demand is distributed uniformly throughout the collection. An earlier study by the author clearly showed that demand was not so distributed. ${ }^{6}$ In fact, 84 percent of the circulation was being met by 33 percent of the collection. This fact is reflected in the data shown in table 2, where all but one item in circulation falls into the young category. Kantor suggests that it is possible to adjust the data to account for the uneven distribu- 
tion of demand. This adjustment is based upon a formula that relates the demand for an item to the chance that it is in circulation. A more complete discussion of the formula and its derivation can be found in Kantor.?

Table 3 shows how the data can be adjusted to account for current demand. The raw or naive data are again shown on the left of the table. A weighting factor or adjustment factor is recorded in a new column following the raw data. This factor is derived by dividing the number of items in circulation for the row by the number of items on the shelf and in the "other" column. This calculation is designed to correct for the fact that the demand for an item actually exceeds its circulation because patrons will be looking for it even though it is not available. Using the young grouping as an example, the number of items in circulation (24) is divided by the total of the number of items on the shelf (132) plus the number in the "other" category (12). The result of this calculation is a weight factor for the row of .1666667 . This calculation is carried out for each grouping and row in the table. Once these calculations have been completed, the raw data are multiplied by the weight factor to provide the adjusted data. Continuing with the example of the young circulation category used previously, we find the number of items in circulation (24) is multiplied by the weight factor $(.1666667)$ to find the adjusted data (4.00000). This calculation is repeated for each category in each of the adjusted rows.

The same calculations that were carried out in table 2 to find circulation availability, "other" availability, and stack availability are repeated using the adjusted data. In this case the circulation dysfunction is calculated by dividing the adjusted circulation total (4.005988) by the adjusted total of the items in the sample (4.005988 $+22.92216+2.077844=29.005992)$. The "other" dysfunction (7.1 percent) is calculated by dividing the adjusted "other" category (2.077844) by the difference between the adjusted total number of items in the sample (29.005992) less the total number in circulation (4.005988). The total stack dysfunction (20.9 percent) is calculated by dividing the adjusted total of the in circulation and "other" columns $(4.005988+2.077844)$ by the adjusted total of the items in the sample (29.005992). The stack availability ( 79 percent) is calculated by subtracting the stack dysfunction (20.9 percent) from 100 percent.

The same procedures described above were used to carry out the analysis in tables 4 and 5 . The only difference was in the method of sorting the data. In the case of table 4 , data were sorted by acquisition date and in the case of table 5 , by imprint date. In each of these cases the circulation was more evenly distributed throughout the three categories although, in each case, almost one-half of the circulation was in the young category.

A third objective of the study was to determine the degree of difference between data gathered during a period when demand was heavy and during a period when demand for library materials was light. The latter is shown in tables 6 through 9. As can be seen and as might be expected, the data differ significantly between the two periods.

\section{CONCLUSIONS}

The time required to conduct a simple availability analysis of the type described in this paper is minimal. The majority of the time will be spent in selecting the sample and searching for the material. This approach would appear to be more efficient than analysis based upon expressed demand, although it clearly provides less management information.

It would also appear that the technique described in this paper is a good management tool for monitoring library performance in two areas: (1) circulation dysfunction and (2) library housekeeping dysfunction. It will provide the library manager with quantitative data to measure against previously established control standards. If, for example, availability falls outside acceptable limits, the manager can take the necessary corrective action. In addition to acting as a flag to the manager that corrective action is required, it also will tell the manager if the corrective action has been successful. This is perhaps just as important as the aforementioned function.

In the case of circulation dysfunction, 
TABLE 2

NAIVE RESULTS OF A SHELFLIST STUDY OF ITEM AVAILABILITY WITH DATA SORTED BY LAST CIRCULATION DATE NOVEMBER

\begin{tabular}{lcccc}
\hline Group & $\begin{array}{c}\text { In Cir- } \\
\text { culation }\end{array}$ & $\begin{array}{c}\text { Status } \\
\text { On } \\
\text { Shelf }\end{array}$ & Other & Total \\
\hline Young & 24 & 132 & 12 & 168 \\
Middle & 1 & 154 & 13 & 168 \\
Elder & 0 & 151 & 17 & 168 \\
Totals & 25 & 437 & 42 & 504 \\
Circulation availability in percent & & & 95.03968 \\
Circulation dysfunction in percent & & & 4.960317 \\
Other availability in percent & & & 91.23173 \\
Other dysfunction in percent & & & 8.768267 \\
Stack availability in percent & & & 86.70635 \\
Stack dysfunction in percent & & & 13.29365 \\
\hline
\end{tabular}

TABLE 3

WEIGHTED RESULTS OF A SHELFLIST STUDY OF ITEM AVAILABILITY WITH DATA SORTED BY LAST CIRCULATION DATE NOVEMBER

\begin{tabular}{|c|c|c|c|c|c|c|c|}
\hline \multirow[b]{2}{*}{ Group } & \multicolumn{3}{|c|}{ Raw (Naive) Data } & \multirow[b]{2}{*}{$\begin{array}{c}\text { Weighting } \\
\text { Factor }\end{array}$} & \multicolumn{2}{|c|}{ Adjusted Data } & \multirow[b]{2}{*}{ Other } \\
\hline & $\begin{array}{l}\text { In Cir- } \\
\text { culation }\end{array}$ & $\begin{array}{l}\text { On } \\
\text { Shelf }\end{array}$ & Other & & $\begin{array}{l}\text { In Cir- } \\
\text { culation }\end{array}$ & $\begin{array}{l}\text { On } \\
\text { Shelf }\end{array}$ & \\
\hline $\begin{array}{l}\text { Young } \\
\text { Middle } \\
\text { Elder } \\
\text { Totals }\end{array}$ & $\begin{array}{r}24 \\
1 \\
0 \\
25\end{array}$ & $\begin{array}{l}132 \\
154 \\
151 \\
437\end{array}$ & $\begin{array}{l}12 \\
13 \\
17 \\
42\end{array}$ & $0^{.0059880}$ & $\begin{array}{c}4.000000 \\
.0059880 \\
0 \\
4.005988\end{array}$ & $\begin{array}{c}22.00000 \\
.9221557 \\
0 \\
22.92216\end{array}$ & $\begin{array}{l}2.000000 \\
.0778443 \\
0 \\
2.077844\end{array}$ \\
\hline \multicolumn{4}{|c|}{$\begin{array}{l}\text { Circulation availability in percent: } \\
\text { Circulation dysfunction in percent: } \\
\text { Other availability in percent: } \\
\text { Other dysfunction in percent: } \\
\text { Stack availability in percent: } \\
\text { Stack dysfunction in percent: }\end{array}$} & & & & $\begin{array}{l}86.18910 \\
13.81090 \\
92.83650 \\
7.163501 \\
79.02560 \\
20.97440\end{array}$ \\
\hline
\end{tabular}

TABLE 4

WEIGHTED RESULTS OF A SHELFLIST STUDY OF ITEM AVAILABILITY WITH DATA SORTED BY ACQUISITION DATE NOVEMBER

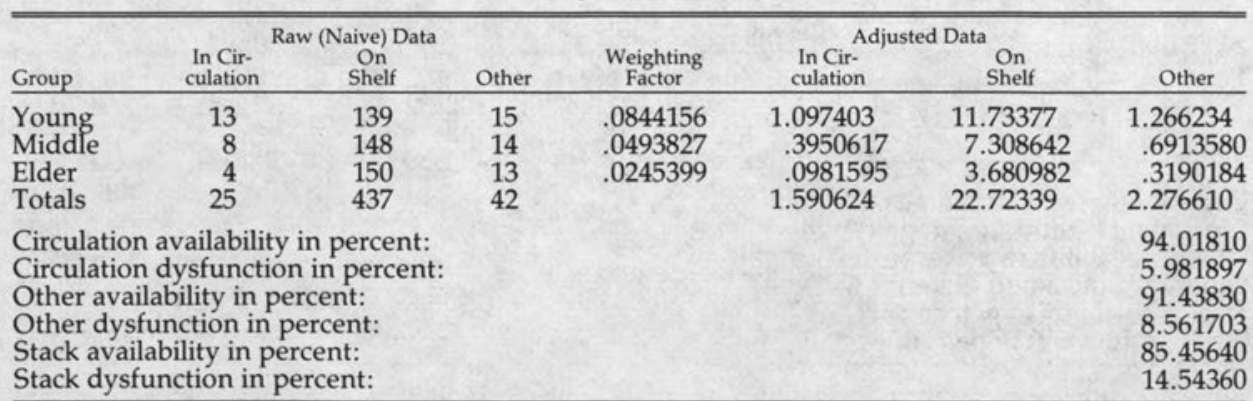


TABLE 5

WEIGHTED RESULTS OF A SHELFLIST STUDY OF ITEM AVAILABILITY WITH DATA SORTED BY IMPRINT DATE ATE NOVEMBER

\begin{tabular}{|c|c|c|c|c|c|c|c|}
\hline Group & $\begin{array}{c}\text { In Cir- } \\
\text { culation }\end{array}$ & $\begin{array}{l}\text { Naive) } \\
\text { On } \\
\text { Shelf }\end{array}$ & Other & $\begin{array}{l}\text { Weighting } \\
\text { Factor }\end{array}$ & $\begin{array}{l}\text { Adju } \\
\text { In Cir- } \\
\text { culation }\end{array}$ & $\begin{array}{l}\text { Data } \\
\text { On } \\
\text { Shelf } \\
\end{array}$ & Other \\
\hline $\begin{array}{l}\text { Young } \\
\text { Middle } \\
\text { Elder } \\
\text { Totals }\end{array}$ & $\begin{array}{r}14 \\
7 \\
4 \\
25\end{array}$ & $\begin{array}{l}138 \\
150 \\
149 \\
437\end{array}$ & $\begin{array}{r}19 \\
9 \\
14 \\
42\end{array}$ & $\begin{array}{l}.0891720 \\
.0440252 \\
.0245399\end{array}$ & $\begin{array}{r}1.248408 \\
.3081761 \\
.0981595 \\
1.654743\end{array}$ & $\begin{array}{c}12.30573 \\
6.603774 \\
3.656442 \\
22.56595\end{array}$ & $\begin{array}{c}1.694268 \\
.3962264 \\
.3435583 \\
2.434052\end{array}$ \\
\hline \multicolumn{4}{|c|}{$\begin{array}{l}\text { Circulation availability in percent: } \\
\text { Circulation dysfunction in percent: } \\
\text { Other availability in percent: } \\
\text { Other dysfunction in percent: } \\
\text { Stack availability in percent: } \\
\text { Stack dysfunction in percent: }\end{array}$} & & & & $\begin{array}{l}93.79194 \\
6.208063 \\
90.86822 \\
9.131779 \\
84.66016 \\
15.33984\end{array}$ \\
\hline
\end{tabular}

TABLE 6

NAIVE RESULTS OF A SHELFLIST STUDY OF ITEM AVAILABILITY WITH DATA SORTED BY LAST CIRCULATION DATE SEPTEMBER

\begin{tabular}{lcccc}
\hline \hline Group & $\begin{array}{c}\text { In Cir- } \\
\text { culation }\end{array}$ & $\begin{array}{c}\text { On } \\
\text { Shelf }\end{array}$ & Status & Other \\
\hline Young & 1 & 152 & 14 & Total \\
Middle & 2 & 166 & 4 & 168 \\
Elder & 5 & 156 & 4 & 168 \\
Totals & 8 & 474 & 22 & 168 \\
Circulation availability in percent & & & 504 \\
Circulation dysfunction in percent & & & 95.03968 \\
Other availability in percent & & & 4.960317 \\
Other dysfunction in percent & & & 9.56452 \\
Stack availability in percent & & & 94.04784 \\
Stack dysfunction in percent & & & 5.952381 \\
\hline
\end{tabular}

TABLE 7

WEIGHTED RESULTS OF A SHELFLIST STUDY OF ITEM AVAILABILITY WITH DATA SORTED BY LAST CIRCULATION DATE SEPTEMBER

\begin{tabular}{|c|c|c|c|c|c|c|c|}
\hline \multirow[b]{2}{*}{ Group } & \multicolumn{3}{|c|}{ Raw (Naive) Data } & \multirow[b]{2}{*}{$\begin{array}{c}\text { Weighting } \\
\text { Factor }\end{array}$} & \multicolumn{2}{|c|}{ Adjusted Data } & \multirow[b]{2}{*}{ Other } \\
\hline & $\begin{array}{l}\text { In Cir- } \\
\text { culation }\end{array}$ & $\begin{array}{l}\text { On } \\
\text { Shelf }\end{array}$ & Other & & $\begin{array}{c}\text { In Cir- } \\
\text { culation }\end{array}$ & $\begin{array}{c}\text { On } \\
\text { Shelf }\end{array}$ & \\
\hline $\begin{array}{l}\text { Young } \\
\text { Middle } \\
\text { Elder } \\
\text { Totals }\end{array}$ & $\begin{array}{l}1 \\
2 \\
5 \\
8\end{array}$ & $\begin{array}{l}152 \\
166 \\
156 \\
474\end{array}$ & $\begin{array}{r}14 \\
4 \\
4 \\
22\end{array}$ & $\begin{array}{l}.0060241 \\
.0117647 \\
.03125\end{array}$ & $\begin{array}{l}.0060241 \\
.0235294 \\
.15625 \\
.1858035\end{array}$ & $\begin{array}{l}.9156627 \\
1.952941 \\
4.875 \\
7.743604\end{array}$ & $\begin{array}{l}.0843373 \\
.0470588 \\
.125 \\
.2563962\end{array}$ \\
\hline \multicolumn{4}{|c|}{$\begin{array}{l}\text { Circulation availability in percent: } \\
\text { Circulation dysfunction in percent: } \\
\text { Other availability in percent: } \\
\text { Other dysfunction in percent: } \\
\text { Stack availability in percent: } \\
\text { Stack dysfunction in percent: }\end{array}$} & & & & $\begin{array}{l}97.73017 \\
2.269826 \\
96.86779 \\
3.132205 \\
94.59797 \\
5.402031\end{array}$ \\
\hline
\end{tabular}


TABLE 8

WEIGHTED RESULTS OF A SHELFLIST STUDY OF ITEM AVAILABILITY WITH DATA SORTED BY ACQUISITION DATE SEPTEMBER

\begin{tabular}{lccccccc}
\hline \hline & $\begin{array}{c}\text { In Cir- } \\
\text { culation (Naive) Data } \\
\text { On } \\
\text { Shelf }\end{array}$ & $\begin{array}{c}\text { Other } \\
\text { Group }\end{array}$ & $\begin{array}{c}\text { Weighting } \\
\text { Factor }\end{array}$ & $\begin{array}{c}\text { In Cir- } \\
\text { culation }\end{array}$ & $\begin{array}{c}\text { An } \\
\text { Shelf }\end{array}$ & Other \\
\hline Young & 1 & 160 & 6 & .0060241 & .0060241 & .9638554 & .0361446 \\
Middle & 5 & 159 & 2 & .0310559 & .1552795 & 4.937888 & .0621118 \\
Elder & 2 & 155 & 10 & .0121212 & .0242424 & 1.878788 & .1212121 \\
Totals & 8 & 474 & 18 & & .1855460 & 7.780531 & .2194685 \\
Circulation availability in percent: & & & & & 97.73325 \\
Circulation dysfunction in percent: & & & & & 2.266752 \\
Other availability in percent: & & & & & 97.31883 \\
Other dysfunction in percent: & & & & & 2.681171 \\
Stack availability in percent: & & & & & 5.91576 \\
Stack dysfunction in percent: & & & & & & \\
\hline
\end{tabular}

the corrective action might involve a reduction in loan periods. ${ }^{8}$ The reduction could encompass all materials or it could be selective, applying only to those materials in high demand. A second approach might be the purchase of more duplicate volumes for high-demand items. A third option would be to use a combination of the two approaches.'

In the case of library housekeeping dysfunction, the manager may want to assign more personnel to shelving or shelf reading. The results might also indicate a need to replace missing materials in a more timely fashion. The technique described in this paper would appear particularly useful if conducted on a periodic basis so that comparative data would be available over time. Data collected in this manner might be a useful tool in assisting the library manager in securing additional staffing or maintaining the same levels of staffing by providing specific data to library and university administrators regarding the impact of staff reductions, in selected areas, on patron success in locating materials in the library.

It is also clear from the analysis that the adjustment for uneven distribution of demand can make a significant difference in the findings regarding availability if the data are sorted by last circulation date. In a working environment, it would appear that the analysis of data when sorted by acquisition date and imprint date more closely approximates that employed in the naive analysis. The key question is which analysis (naive, last circulation date, ac- quisition date, or imprint date) most closely approximates a true picture of stack availability? Table 10 offers a comparison of the availability analysis for the four approaches. Since the problem is to correct for the effects of actual use, the author would hypothesize that adjusted data sorted by last circulation date would provide the best approximation of actual availability. It would be useful if a library were to conduct an expressed demand analysis in conjunction with a study similar to that described in this paper. Such a study would help answer this question.

It would also appear likely that management could easily make several erroneous assumptions if the results of naive data analysis were used. Two problems are evident: (1) the availability is overstated and (2) the major cause of the dysfunction is incorrectly identified. As an example, in the latter situation, if a manager wished to increase stack availability based upon the data presented in table 2 , naive data, he or she would most likely commit the library resources to reducing the number of items in the "other" category. This would be the logical assumption because this category represents a larger proportion of the dysfunction than does the circulation category. However, when the manager examines the adjusted data sorted by last circulation date presented in table 3 , it becomes clear that the major source of stack dysfunction and, hence, user frustration is the fact that materials are in circulation.

As shown in the data, there is a significant difference between the results of data 
TABLE 9

WEIGHTED RESULTS OF A SHELFLIST STUDY OF ITEM AVAILABILITY WITH DATA SORTED BY IMPRINT DATE SEPTEMBER

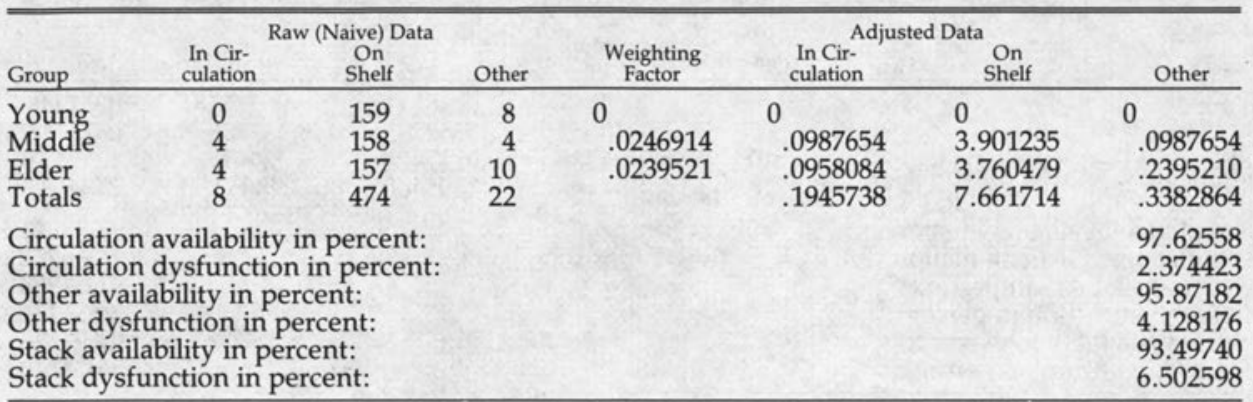

TABLE 10

SUMMARY TABLE SHOWING ITEM AVAILABILITY DURING A HIGH CIRCULATION PERIOD

\begin{tabular}{lccrr}
\hline & Naive & $\begin{array}{c}\text { Last } \\
\text { Circula- } \\
\text { tion Date }\end{array}$ & $\begin{array}{c}\text { Acquisi- } \\
\text { tion Date }\end{array}$ & $\begin{array}{c}\text { Imprint } \\
\text { Date }\end{array}$ \\
\hline Circulation availability & 95.03 & 86.18 & 94.01 & 93.79 \\
Circulation dysfunction & 4.96 & 13.81 & 5.98 & 6.20 \\
Other availability & 91.23 & 92.83 & 91.43 & 90.96 \\
Other dysfunction & 8.76 & 7.16 & 8.56 & 9.13 \\
Stack availability & 86.70 & 79.02 & 85.45 & 84.66 \\
Stack dysfunction & 13.29 & 20.97 & 14.54 & 15.33 \\
\hline
\end{tabular}

TABLE 11

WEIGHTED RESULTS OF A SHELFLIST STUDY OF ITEM AVAILABILITY WITH DATA SORTED BY LAST CIRCULATION DATE NOVEMBER

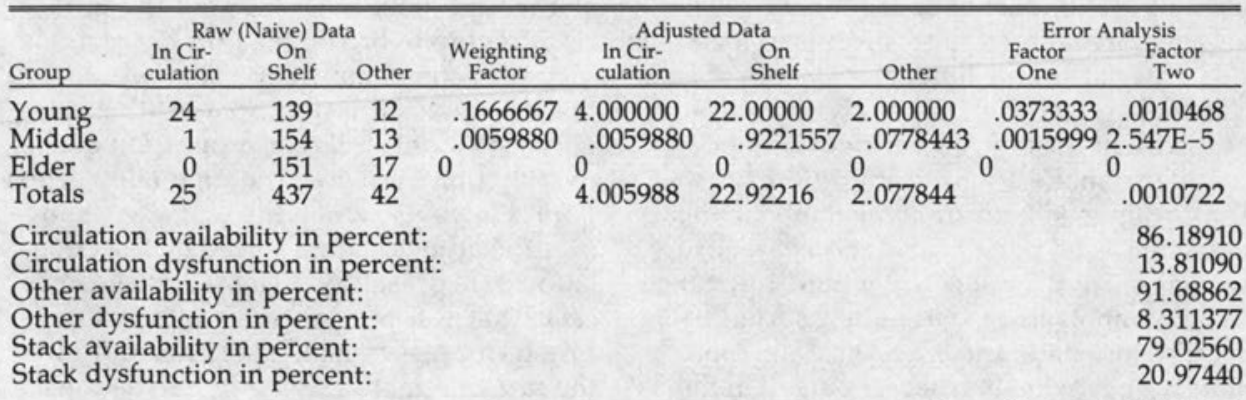


gathered during periods of low use and high use. The question naturally arises during which period should the study be conducted? Since most of the demand and hence the circulation and library housekeeping dysfunction will occur during periods of high demand, the author feels this would be the most appropriate time to conduct the study.

\section{ERROR ANALYSIS}

Kantor provides the following formula as a means of establishing a rough estimate of the standard error. ${ }^{10}$

$$
\begin{gathered}
E^{\wedge} 2=W(1-W) A / N^{\wedge} 2 \bullet((2-W) W- \\
(1-P))^{\wedge} 2
\end{gathered}
$$

The standard error is calculated for each row within each group. In the formula, $W$ = the weight factor for the row, $A=$ the row sum for the raw data, $N=$ the total number of circulations for all groups, and $P=$ the adjusted circulation availability.
Table 11 illustrates the use of the standard error calculation. Using the row for the young group as an example, the data show that $W=.1666667, A=168(24+$ $132+12), N=25$, and $P=.8618910$. In the table factor one is calculated as follows: $W^{\star}(1-W)^{\star} A /\left(N^{\star} N\right)$ and recorded in the next to the last column for the row as .0373333 . The product for the last column is calculated using the formula $\left((2-W)^{*}\right.$ $W-(1-p))^{\wedge} 2$ times the product from the previous column and results in a product of .0010468 . This process is repeated for each row. As can clearly be seen, the calculation for the first row has the greatest impact upon the error calculations.

The complete error formula utilizes the products shown in the last column for each row. $E^{\wedge} 2=(P 1+P 2+P 3) /\left(N^{\star} N\right)$. In the case of table 10 , this is $E^{\wedge} 2=(.0010468$ $+.00002547+0) /\left(25^{\star} 25\right)$ or $E=1716 \mathrm{E}-$ 6.

\section{REFERENCES}

1. P. B. Kantor, "Demand-Adjusted Shelf Availability Parameters," Journal of Academic Librarianship 7:78-82 (May 1981).

2. M. K. Buckland and others, Book Availability and the Library User (New York: Pergamon, 1978); J. A. Urquhart and J. L. Schofield, "Measuring Readers Failure at the Shelf," Journal of Documentation 27:273-86 (Dec. 1971); P. B. Kantor, "Availability Analysis," Journal of the American Society for Information Science 27:311-19 (Sept. 1976); T. Saracevic; W. Shaw, Jr.; and P. B. Kantor, "Causes and Dynamics of User Satisfaction in an Academic Library," College \& Research Libraries 36:7-18 (Jan. 1977); J. B. Whitlatch and K. Kieffer, "Service at San Jose State University: A Survey of Document Availability," Journal of Academic Librarianship 4:196-99 (Sept. 1978); E. Palais, "Availability Analysis Report," in Association of Reserach Libraries, Office of Management Studies, User Surveys and Evaluation of Library Services (Washington, D.C.: ACRL, 1981), p.73-82; R. Smith and W. Granade, "Undergraduate Library Availability Study 1975-1977," in Association of Research Libraries, Office of Management Studies, User Surveys and Evaluation of Library Services (Washington, D.C.: ACRL, 1981), p.83-90.

3. N. K. Kaske, "Effectiveness of Library Operations: A Management Information Systems Approach and Application" (Library Science dissertation, University of Oklahoma, 1973); E. Altman and others, A Data Gathering and Instructional Manual for Performance Measures in Public Libraries (Chicago: Celadon Press, 1976).

4. Kantor, "Demand-Adjusted Shelf Availability Parameters," p.78-82.

5. Ibid., p. 80 .

6. P. Schwarz and L. Olson, Examination of Potential Management Decisions Based upon a Core Collection Derived from Last Circulation Date Data (ERIC Document 214 496).

7. Kantor, "Demand-Adjusted Shelf Availability Parameters," p.82.

8. Buckland, Book Availability.

9. E. Palais, "Increasing the Effectiveness of a University Library: Evaluation of an Added Copy Project," in Options for the 80s Program of the Association of College and Research Libraries 2nd Annual Conference, October 1-4, 1981 (Minneapolis, Minn.: ACRL, 1981).

10. Kantor, "Demand-Adjusted Shelf Availability Parameters," p.82. 